\title{
Growth and very low birth weight
}

\author{
W H KITCHEN,${ }^{*} \dagger \mathrm{G}$ W FORD,${ }^{*}$ AND L W DOYLE* \\ ${ }^{*}$ Departments of Obstetrics and Gynaecology and †Paediatrics, University of Melbourne, Australia
}

SUMMARY Information on the likelihood of catch up growth in poorly grown very low birthweight children is sparse. The centiles for weight, height, and head circumference were recorded at both 2 and 5 years of age for 135 very low birthweight children and 42 normal birthweight children. At both ages significantly more children of very low birth weight were under the 10th centile for weight and height. Children of birth weight under $1000 \mathrm{~g}$ were more often under the 10th centile for weight at 5 years compared with those of birth weight 1000 $1500 \mathrm{~g}$. Mean incremental weight gain between 2 and 5 years was significantly less for very low birthweight children. Mean increment in weight from 2 to 5 years was less for very low birthweight children who had been under the 10 th centile for weight at 2 years; children who had been under the 10th centile for height also had lower mean height increments. The growth centiles achieved by 2 years of age were useful predictors of poor growth at 5 years, with perinatal data of marginal importance. Only six of $43(14 \%)$ children with a weight at 5 years of age under the 10th centile were small for gestational age at birth. Very low birthweight children who had a weight or height under the 10th centile at 2 years of age usually remained in this category at 5 years with no evidence of catch up growth.

In early childhood, many very low birthweight survivors (birth weight under $1501 \mathrm{~g}$ ) are reported to grow poorly. ${ }^{12}$ Parents of such children often ask whether catch up growth will occur but there is little information available on this subject for children born in the era of sophisticated neonatal intensive care.

To assist in counselling parents of poorly growing children of very low birth weight, we assessed the physical growth of a cohort of these children and a comparison group of normal birthweight children when aged 2 years and again at 5 years. The growth centile attained and incremental growth over this period were examined for evidence of catch up growth; we also looked for possible early predictors of poor growth at 5 years of age.

\section{Patients and methods}

The cohort of very low birthweight children comprised 154 consecutive survivors of birth weight under $1501 \mathrm{~g}$ born in The Royal Women's Hospital, Melbourne between 1 October 1980 and 31 March 1982. Anthropometric data were available at both 2 and 5 years for 135 children $(87 \%)$, but for one of these children the height at 2 years was not available. Of the 19 children not included in the study, two were too disabled to measure weight and height accurately, six were untraced or the parents refused assessment, and 11 had growth data at 2 or 5 years only. The mean birth weight of children was $1183 \mathrm{~g}$ and mean gestational age was 29.3 weeks. Very low birthweight children with paired growth data were seen at the mean ages of $2 \cdot 2$ and 5.2 years, corrected for prematurity.

Sixty children of normal birth weight (birth weight over $2500 \mathrm{~g}$ ) were selected for longitudinal study in a quasirandom fashion, using the terminal digits of the mother's unit record number. These normal birthweight children were born in the same hospital during the same years as the very low birthweight children. Growth data were available for $42(70 \%)$ children at mean ages of $2 \cdot 0$ years and $5 \cdot 1$ years. One child of normal birth weight was too disabled to measure accurately, two had growth data at one age only, and 15 were untraced or the assessment was refused.

Weight, standing height, and occipitofrontal head circumference were measured in a standard fashion. ${ }^{3}$ Centile positions for weight and height were derived from standards for an urban multiracial Australian community. ${ }^{45}$ Centiles for head circumference were obtained from the composite charts of Nellhaus. ${ }^{6}$ The increments in weight, height, and head circum- 
ference between the ages of 2 and 5 were computed. ${ }^{7}$ Because the interval between assessments was not exactly three years in every child, the increments in growth between 2 and 5 years of age were divided by the time between assessments to calculate the average annual growth increment.

Data were analysed by computer using SPSSX package programs. Differences in proportions were analysed by corrected $\chi^{2}$ tests; differences in normally distributed continuous data were compared by $t$ tests. To compare data not normally distributed, Mann-Whitney U tests were used. McNemar tests were used to determine whether significant proportions of children changed from 2 to 5 years relative to the 10th centile for growth. Discriminant analysis was used to obtain predictors of growth measurements under the 10th centile at 5 years of age. In the three discriminant analyses the dichotomous dependent variables were weight, height, and head circumference at 5 years, respectively above or below the 10th centile. Perinatal independent variables included growth centiles at birth, birth weight, gestational age, use of mechanical ventilation, necrotising enterocolitis, recurrent apnoea, duration of ventilation and of oxygen treatment, bronchopulmonary dysplasia, day of lowest postnatal weight, social status, duration of maternal education, and immigrant status. Mothers were designated as immigrants if they were born in a country where English was not the first language. The additional independent variables available at 2 years of age included growth centiles at 2 years, the number of days of hospital readmission, number of hospital readmissions, and number of episodes of wheezing. A p value less than $0 \cdot 05$ on any statistical test was regarded as significant.

\section{Results}

Table 1 shows the number of children with size indices below the 10th centile. There were significantly more children of very low birth weight with weights and heights under the 10th centile at both 2 and 5 years but not for head circumference. For these children the proportion with a head circumference under the 10th centile increased significantly from 2 to 5 years $(\mathrm{p}=0.0002)$; over this period, children of birth weight $1000-1500 \mathrm{~g}$ deteriorated significantly $(p=0.008)$ with a similar but nonsignificant trend for those of birth weight under $1000 \mathrm{~g}$. A significant deterioration in head growth was not observed in the normal birthweight children; the proportions relative to the 10th centile did not change significantly for any other growth measurement between 2 and 5 years, either for the children of normal or very low birth weight.

Significantly more children of birth weight under $1000 \mathrm{~g}$ were below the 10 th centile for weight and height at 2 years compared with children of birth weight 1000 to $1500 \mathrm{~g}$; however, this difference persisted at 5 years only for weight.

Using the 3rd centile as a more stringent criterion for poor growth, at 5 years of age 27 out of 135 $(20 \%)$ of the very low birthweight children were below this point for weight, 14 out of $135(10 \%)$ for height, and 11 out of $135(8 \%)$ for head circumference; 12 out of $135(9 \%)$ of the very low birthweight children were under the 3rd centile for both weight and height. No child of normal birth weight was under the 3rd centile for any of these measurements.

We next investigated the centile ranking, rather than the percentage of children under the 10th centile (as was shown in table 1); children in both groups were compared using Mann-Whitney U tests. The very low birthweight children had significantly lower centiles for weight at 2 years $(z=-5 \cdot 90$, $\mathrm{p}<0.0001)$, and at 5 years $(\mathrm{z}=-4.69, \mathrm{p}<0.0001)$, for height at 2 years $(\mathrm{z}=-5.44, \mathrm{p}<0.0001)$ and at 5 years $(z=-3.57, p=0.004)$, but for head circumference only at 5 years $(\mathrm{z}=-2 \cdot 85, \mathrm{p}=0 \cdot 004)$.

Table 1 No (\%) of children with size indices under the 10th centile at 2 and 5 years of age

\begin{tabular}{|c|c|c|c|c|c|c|}
\hline \multirow[t]{2}{*}{ Group } & \multicolumn{2}{|l|}{ Weight } & \multicolumn{2}{|l|}{ Height } & \multicolumn{2}{|c|}{ Head circumference } \\
\hline & 2 years & 5 years & 2 years & 5 years & 2 years & 5 years \\
\hline $\begin{array}{l}\text { Normal birth weight }(n=42) \\
\text { Very low birth weight }(n=135)\end{array}$ & $\begin{array}{l}0 \\
35(26) \\
p=0 \cdot 005 \dagger\end{array}$ & $\begin{array}{l}2(5) \\
43(32) \\
p=0 \cdot 009 \dagger\end{array}$ & $\begin{array}{l}0 \\
34(25)^{*} \\
\mathrm{p}=0 \cdot 007 \dagger\end{array}$ & $\begin{array}{l}2(5) \\
31(23) \\
p=0 \cdot 02 \dagger\end{array}$ & $\begin{array}{l}0 \\
4(3) \\
\text { NS }\end{array}$ & $\begin{array}{l}3(7) \\
17(13) \\
\text { NS }\end{array}$ \\
\hline $\begin{array}{l}\text { Very low birth weight: } \\
\text { Birth weight } 500-999 \mathrm{~g}(\mathrm{n}=28) \\
\text { Birth weight } 1000-1500 \mathrm{~g}(\mathrm{n}=107)\end{array}$ & $\begin{array}{l}16(57) \\
19(18) \\
p=0 \cdot 001 \dagger\end{array}$ & $\begin{array}{l}16(57) \\
27(25) \\
p=0 \cdot 003 \dagger\end{array}$ & $\begin{array}{l}13(46) \\
21(20)^{*} \\
\mathrm{p}=0 \cdot 008 \ddagger\end{array}$ & $\begin{array}{l}9(32) \\
22(21) \\
\text { NS }\end{array}$ & $\begin{array}{l}0 \\
4(4) \\
\text { NS }\end{array}$ & $\begin{array}{l}5(18) \\
12(11) \\
\text { NS }\end{array}$ \\
\hline
\end{tabular}

*No height at 2 years for one child, birth weight $>1000 \mathrm{~g}$, normal height at 5 .

$\dagger$ Normal birth weight compared with very low birthweight children.

. $¥$ Infants of birth weight 500 to $999 \mathrm{~g}$ compared with those of birth weight 1000 to $1500 \mathrm{~g}$. 
The mean incremental growth between the assessments at 2 and 5 years of age is shown in table 2 . Increments in weight were significantly less in children of very low birth weight compared with those of normal birth weight, but were similar for height and head circumference, indicating no evidence of catch up in height or head growth and a significant deterioration in weight gain. Children of birth weight under $1000 \mathrm{~g}$ had similar growth increments compared with those of birth weight 1000 to $1500 \mathrm{~g}$ (table 2). Those children of very low birth weight who had weighed under the 10th centile at 2 years had significantly lower weight increments compared with the remainder; those who had been under the 10th centile for height at 2 years had significantly lower height increments (table 2).

Possible predictors of growth that was under the 10 th centile at 5 years of age were determined using discriminant analyses. The corresponding growth centile achieved by 2 years was the most important clinical and statistical predictor; a few perinatal variables and one health variable accounted for a small percentage of the variance, which was of statistical rather than clinical significance. Predictors of a 5 year weight under the 10th centile were weight centile at 2 years $(29 \cdot 2 \%$ of variance, $\mathrm{p}=0.0001)$, birthweight centile $(2 \cdot 3 \%$ additional variance, $\mathrm{p}=0.007)$, immigrant status $(2.4 \%$ additional variance, $p=0.02)$, and the use of mechanical ventilation $(2 \cdot 9 \%$ additional variance, $p=0.007)$.
For 5 year old height under the 10th centile, predictors were the 2 year height centile $(19.3 \%$ of variance, $p=0.001)$ and immigrant status $(2.4 \%$ additional variance, $p=0.025$ ). For the 5 year head circumference under the 10th centile, significant predictors were head centile at 2 years $(28.3 \%$ of variance, $\mathrm{p}=0.0001)$ and the number of wheezing episodes in the first 2 years of life $(2 \cdot 6 \%$ additional variance, $p=0 \cdot 021$ ).

Only six out of $43(14 \%)$ children with a weight at 5 years under the 10th centile were also under the 10 th centile for birth weight. There were 12 children who had birth weights under the 10th centile and by 5 years six remained in this category, four had grown normally, and two were untraced.

\section{Discussion}

Children of very low birth weight, judged by the centile attained in early childhood, have been reported to grow poorly in weight and height, with fewer problems with head growth. ${ }^{18-12}$ Those of birth weight under $1000 \mathrm{~g}$ are even more likely to grow poorly in weight and height. ${ }^{1314}$ These reports, however, do not provide the data on incremental growth or growth velocity that are needed to assess whether poorly growing survivors of very low birth weight catch up in later childhood.

In our study, very low birthweight children at 2 and 5 years of age were significantly lighter and

Table 2 Mean annual growth increments between 2 and 5 years

\begin{tabular}{|c|c|c|c|}
\hline Group & $\begin{array}{l}\text { Mean (SD) weight } \\
(\text { kg/year })\end{array}$ & $\begin{array}{l}\text { Mean (SD) height } \\
\text { (cm/year) }\end{array}$ & $\begin{array}{l}\text { Mean }(S D) \text { head } \\
\text { circumference }(\mathrm{cm} / \text { year })\end{array}$ \\
\hline $\begin{array}{l}\text { Normal birth weight }(n=42) \\
\text { Very low birth weight }(n=134)\end{array}$ & $\begin{array}{l}2 \cdot 29(0 \cdot 84) \\
2 \cdot 00(0 \cdot 67) \\
t=2 \cdot 02 \\
p=0.048\end{array}$ & $\begin{array}{l}7.58(1.21) \\
7.55(1.02) \\
\text { NS }\end{array}$ & $\begin{array}{l}0.70(0.33) \\
0.69(0.23) \\
\text { NS }\end{array}$ \\
\hline $\begin{array}{l}\text { Very low birth weight: } \\
\text { Birth weight }<1000 \mathrm{~g}(\mathrm{n}=28) \\
\text { Birth weight } 1000-1500 \mathrm{~g}(\mathrm{n}=106)\end{array}$ & $\begin{array}{l}1.97(0 \cdot 74) \\
2 \cdot 02(0 \cdot 66) \\
\text { NS }\end{array}$ & $\begin{array}{l}7.64(0 \cdot 96) \\
7 \cdot 52(1.04) \\
\text { NS }\end{array}$ & $\begin{array}{l}0.73(0.23) \\
0.68(0 \cdot 22) \\
\text { NS }\end{array}$ \\
\hline $\begin{array}{l}\text { Height }<10 \text { th centile at } 2 \text { years }(n=34) \\
\text { Height }>10 \text { th centile at } 2 \text { years }(n=100) \\
\text { Head circumference }<10 \text { th centile at }\end{array}$ & $\begin{array}{l}1.75(0.49) \\
2.09(0.70) \\
t=-2 \cdot 56 \\
p=0.012\end{array}$ & $\begin{array}{l}7.13(0.62) \\
7.68(1.09) \\
t=-2 \cdot 96 \\
p=0.007\end{array}$ & \\
\hline 2 years $(n=4)$ & & & Insufficient for analysis \\
\hline
\end{tabular}


shorter than their normal birthweight controls. Moreover, compared with our own normal birthweight population, standards for a multiracial Australian urban population, ${ }^{4}$ and the charts of Tanner et al, ${ }^{3}$ those under the 10 th and 3 rd centiles for weight and height were substantially over represented. Children of birth weight under $1000 \mathrm{~g}$ were significantly lighter at 5 years compared with those of birth weight 1000 to $1500 \mathrm{~g}$.

There was no convincing evidence of catch up growth for very low birthweight children between 2 and 5 years. Parents of these children who are growing poorly at 2 years may ask for reassurance that catch up growth will occur; rather than provide this reassurance, our data show that weight or height increments between 2 and 5 years are likely to remain below average, perpetuating poor growth.

We previously reported that very low birthweight children, born in the era when mechanical ventilation was not utilised and when survival prospects were lower (1966-70), attained near normal growth centiles at 14 years of age. ${ }^{15}$ These children are not comparable with survivors of the intensive care era; consequently, the current cohort should be followed up to determine what changes in growth occur during puberty.

Significantly more children of very low birth weight had a head circumference under the 10th centile at 5 years compared with 2 years. We speculate that the decrease in centiles of these children may relate to their skulls assuming a less dolicocephalic shape from 2 to 5 years and are not necessarily a reflection of decreased brain growth.

Being under the 10th centile for any of the three size indices at 5 years was not dominantly determined by being under the 10th centile for that index at birth. The 43 children with weights under the 10 th centile at 5 years included only six who were small for gestational age at birth. The centile attained for weight at 2 years was the predominant 'predictor' of poor weight gain over the next three years, with other factors of only marginal clinical importance.

With the increasing availability of synthetic growth hormone, it is likely that this treatment will be evaluated in children who do not have demonstrable growth hormone deficiency. Our study indicates that, without intervention, children of very low birth weight who are small at 2 years will generally remain so at 5 years. If a trial of growth hormone is contemplated these children provide a readily indentified risk group for poor growth; they can usually be identified by 2 years of age and they are unlikely to exhibit spontaneous catch up in weight or height over the next three years.

The work was supported in part by the National Health and Medical Research Council and the Royal Women's Hospital3AW Clinical Research Foundation.

\section{References}

1 Vaucher Y. Growth in the high risk newborn. In: Sell EJ, Brazleton TB, eds. Follow-up of the high risk newborn-a practical approach. Springfield: Charles T Thomas, 1980: 101-17.

2 Hack M, Merkatz IR, Gordon D, Jones PK, Fanaroff AA. The prognostic significance of postnatal growth in very lowbirthweight infants. Am J Obstet Gynecol 1982;143:693-9.

3 Tanner JM, Whitehouse RH, Takaishi M. Standards from birth to maturity for height, weight, height velocity and weight velocity. British children 1965. Arch Dis Child 1966;41:454-71.

${ }^{4}$ Jones DL, Hemphill W, Meyers ESA. Height, weight and other physical characteristics of New South Wales children. Part 1. Children aged 5 years and over. New South Wales: Government Printer, 1973.

5 Jones DL, Hemphill W. Height, weight and other physical characteristics of New South Wales children. Part II. Children under 5 years of age. New South Wales: Government Printer, 1974.

${ }^{6}$ Nellhaus G. Head circumference from birth to 18 years. Pediatrics 1968;41:106-14.

${ }^{7}$ Roche AF, Himes JH. Incremental growth charts. Am J Clin Nutr 1980;33:2041-52.

${ }^{8}$ Gross SJ, Oehler JM, Eckerman CO. Head growth and developmental outcome in very low birth-weight infants. Pediatrics 1980;71:70-5.

9 Kimble KJ, Ariagno RL, Stevenson DK, Sunshine P. Growth to 3 years among very low-birth-weight sequel-free survivors of modern neonatal intensive care. $J$ Pediatr 1982;100:622-4.

10 Ross G, Krauss AN, Auld PA. Growth achievement in lowbirth-weight premature infants: relationship to neurobehavioral outcome. J Pediatr 1983;103:105-8.

11 Tudehope DI, Burns Y, Callaghan M, Mohay H, Silcock A. The relationship between intrauterine and postnatal growth on the subsequent psychomotor development of very low birthweight (VLBW) infants. Aust Paediatr J 1983;19:3-8.

12 Saigal S, Rosenbaum P, Stoskopf B, Milner R. Follow-up of infants 501 to 1500 gram birthweight delivered to residents of a geographically defined region with intensive perinatal care facilities. J Pediatr 1982;100:606-13.

13 Hoskins EM, Elliot E, Shennan AT, Skidmore MB, Keith E. Outcome of very low birth-weight infants born in a perinatal center. Am J Obstet Gynecol 1983;145:135-40.

14 Ford G, Rickards A, Kitchen WH, Ryan MM, Lissenden JV. Relationship of growth and psychoneurologic status in 2-yearold children of birthweight 500-999g. Early Hum Dev 1986;13: 329-37.

15 Kitchen WH, Ryan MM, Rickards AL. Longitudinal study of very low birthweight infants: impairments, health and distance growth to 14 years of age. Aust Paediatr J 1987;23:335-8.

Correspondence to Dr WH Kitchen, Department of Obstetrics and Gynaecology, University of Melbourne, Parkville 3052, Australia.

Accepted 21 August 1988 